\title{
LAS HUELLAS DE LOS GALOS
}

\section{Enrique Guiter}

Una Europa centro-occidental, hasta entonces bascófona, conoció, en el curso de los mil quinientos años que precedieron a nuestra era, varias invasiones venidas por vías diferentes ${ }^{1}$.

Algunas llegaron por el Mediterráneo. Ya desde el siglo XV, los íberos alcanzan Andalucía y lentamente caminan a lo largo de la costa mediterránea para acercarse a Lenguadoc en el siglo $\mathrm{V}$. A principios del primer milenario los etruscos desembarcan en Italia.

Las invasiones itálicas traspasan los Alpes orientales, primero los latinos, antes de la venida de los etruscos, más tarde los oscos y umbrios, después de la misma. Pero los latinos no vendrán a la Península Ibérica antes del final del siglo III.

Por fin, los celtas se adelantan por la gran llanura europea en dos olas sucesivas, la ola gaélica en los primeros siglos del milenario, la ola galo-britónica en la segunda mitad del mismo milenario, al pasar de la protohistoria a la historia. Quisiéramos interesa mos por esta última migración.

Los historiadores romanos nos proporcionaron noticias precisas, aunque divergentes a veces, sobre la incursión célebre de los galos en la Italia central en 390. Aquel episodio por lo menos nos enseña que las poblaciones célticas,

1 Henri Guiter. Onomastique et contacts de langues: exemple des confins pyrénéo-méditerranéens. Conferencia dada en el XII Congreso Internacional de Onomástica (Berna, 1975). Onoma (XX,1), Louvain, 1976, p.p. 106-127.

Enrique Guiter. Contactes lingüístics del Pireneu mediterrani. Miscellanea Barcinonensia (XLIX), Barcelona, 1978, p.p. 37-57. 


\section{ENRIQUE GUITER}

que caminaban hacia el sur en aquel entonces, se llamaban de suyo Galli, ya que los romanos, humillados por una derrota ultrajante y por una liberación comprada a peso de oro, hallaron el consuelo de una venganza ingeniosa llamando desde entonces gallus al animal "buscarrazones y perdonavidas", hinchado todo de una vanidad ridícula, que recordaba la del invasor efímero.

Por supuesto, los galos ocuparon el país al cual dieron su nombre, Galia, pero no alcanzaron a todas sus partes simultáneamente. Las investigaciones arqueológicas efectuadas en Lenguadoc ${ }^{2}$ nos enseñan que las tribus galas llevaban una vida pastoril sobre las altiplanicies del Macizo Central y no llegaron a desembocar en la llanura costanera sino a mediados del siglo III: en la estación lenguadociana más estudiada, la de Enserune, la presencia celta sucede a la presencia ibérica por los años 250 . Aquella instalación no es anterior a más de un siglo de la ocupación romana, que había de parar por seis siglos todas las grandes migraciones humanas. Ya tuvimos ocasión de estudiar ${ }^{3}$ un aspecto lingüístico de aquella celtización tardía de la costa lenguadociana.

La organización romana, en cierto modo, había cristalizado la ocupación del territorio en su estado del tiempo de la conquista: la toponimia nos da la posibilidad de que descubramos la repartición de los elementos imputables a los galos.

"Pero de todos aquellos elementos galos, escribe Dauzat", es el sufijo -acos, latinizado en -acum ou -acus, el que conoció la suerte más brillante en la época romana... Aunque se añadió, en nuestros nombres de lugares, a ciertas palabras de valor topográfico, en la inmensa mayoría de los casos, sigue a un nombre de persona...

Si ahora nos referimos a la forma, - acum se ha vuelto - ac en el Mediodía [de Galia]..."

Apoyándonos en la repartición geográfica de aquellas formaciones toponímicas en $-a c$, pudimos establecer los trayectos de los invasores galos por el Mediodía de Galia ${ }^{5}$. Los cantones administrativos en los cuales asoman, se disponen en el mapa como cuentas de rosario.

Saliendo del Macizo Central, la vía principal hacia el sur fue el curso del río Garona; fácilmente se concibe que aquellas poblaciones, al trasladarse con rebaños grandes, hayan apreciado la proximidad de un río caudal como abre-

2 Maurice Louis. Préhistoire du Languedoc méditerranéen et du Roussillon. Edición de los "Cahiers d'Histoire et d'Archéologie", Nî̀es, 1948, 204 p.

3 Enrique Guiter. Les pasteurs des plateaux. Actas del 32 Congreso de la "Fédération Historique du Languedoc-Roussillon", Montpellier, 1958, pp. 83-90.

4 Albert Dauzat. Les noms de lieux. París, 1942, p. 113.

5 Henri Guiter. Lignes de force de l'implantation gauloise en Gascogne, Languedoc et Provence. Miscelánea Seguy (II), Annales de l'Université de Toulouse XIV, Toulouse, 1978, pp. 177-192. 
vadero del ganado. De esta corriente mayor arrancan corrientes laterales, hasta topar contra la muela pirenaica.

Pasar los Pirineos centrales con ramados numerosos es una empresa dificilísima por la sola existencia del obstáculo natural, y aún más si se añade un obstáculo humano debido a la hostilidad de las poblaciones establecidas de antemano. Desde el curso superior del Garona vemos las líneas de corriente humana que se extienden hacia el este y el oeste, como si buscasen el punto flaco de la barrera imponente.

Por el lado del este, tanto la subida del Arieja como la del Auda no acaban por un resultado favorable. Tuvimos ocasión de mostrar ${ }^{6}$ cómo los topónimos en - $a c$, tan numerosos en el valle del Arieja y la cuenca del Auda, desaparecen espectacularmente al sur de la frontera catalano-lenguadociana. El trazo espeso continuo de nuestro mapa sigue a la cumbre de la cordillera pirenaica principal, que deja al sur la totalidad de las tierras catalanas.

En dirección del oeste, la flecha que sigue al piamonte pirenaico viene a acabarse en el cantón de Arudy, al pie del puerto del Portalé. Nuestro estudio de la "Miscelánea Seguy" había parado aquí su investigación. Ahora quisiéramos intentar proseguirla al sur de los Pirineos centro-occidentales.

En seguida, nos llama la atención la existencia de dos nombres derivados de gallu: al sur del Puerto del Portalé el río Gállego (lat gállicu: propio de Galia o de los galos), y al extremo occidental de la Cordillera Cantábrica el pueblo de los Gallegos (lat. galláicos: habitantes del noroeste de España). Intentaremos ver si, entre esos dos términos, aparecen huellas toponímicas que puedan relacionarse con los galos. Por supuesto, dejaremos de lado los múltiples "Gallegos" u otros derivados similares, que la Reconsquista esparció por León y Castilla, pero no el topónimo Gallur, entre Zaragoza y Tudela.

Preguntémonos primero por qué aquella elección del valle del Gállego como vía de penetración hacia el sur.

Al norte de los Pirineos y a lo largo de éstos, nos damos cuenta de la presencia gala; materializada por los topónimos en $-a c$, abunda hasta el valle d'Ossau, cuyo río, el "Gave" de Ossau, conduce al puerto del Portalé; desaparece en el valle más occidental de Aspe, que llega al puerto de Somport.

Aún más al oeste empieza el País Vasco actual.

Pues, los galos, que no habian podido desembocar por el Puerto de Pimorent $(1915 \mathrm{~m}$ ) en el valle del Segre, ni por el Puerto de Bonaigua (2072 m) en el valle de la Noguera, ni tampoco alcanzar el valle de Aspe y el Somport $(1631 \mathrm{~m})$, van a coger el puerto del Portalé $(1794 \mathrm{~m})$ e ir río Gállego abajo. ¿Qué facilidad más grande encontraron aqui?.

6 Henri Guiter. Frontière linguistique et frontière toponymique. Actas del Coloquio de la "Société Française d'Onosmatique", Loches, 1978, pp. 101-113. 


\section{ENRIQUE GUITER}

Para contestar a esta pregunta, recordemos el poblamiento antiguo de los Pirineos. Plinio" lo resume de un modo muy claro: "per Pyrenaeum Ceretani, deinde Vascones" ¿Por dónde pasaba la frontera entre las dos poblaciones? Seguía el curso del Gállego. J. Caro Baroja ${ }^{8}$ presenta un mapa de las divisiones étnicas al norte de España: el límite oriental de los vascones coincide con el Gállego. Además, el autor precisa: "Con relación a los vascones, bastaría decir aquí que este pueblo, que limitaba al 0 . con los várdulos, ocupaba una extensión muy parecida a la que tiene la actual provincia de Navarra, cogiendo además el extremo N.E. de Guipúzcoa (valle de Oyarzun y promontorio de Zaizquíbel), algo de la de Logroño, y algo, también, de las de Zaragoza y Huesca, con Jaca y Ejea, inclusive". La ventaja que ofrecía la bajada del Gállego, además de la presencia asegurada del agua, era la posibilidad para los inmigrantes de insertarse entre las dos potentes etnias pirenaicas. No habian podido forzar el territorio de ninguna: aprovechaban la zona de resistencia menor presentada por los confines.

Recontemos ahora los datos toponímicos que puedan jalonar el trayecto de los galos entre las dos muestras de gállicu y de galláicu. Pensamos primero en las formaciones en -acu (femenino - aca), que regularmente tienen que dar -ago/-aga:

$\begin{array}{ll}\text { Zaragoza } & : \text { Litago; } \\ \text { Soria } & : \text { Sarnago, Buitrago; } \\ \text { Logroño } & : \text { Cornago; } \\ \text { Burgos } & \text { :Solago, Navagos; } \\ \text { Santander } & : \text { Cerbiago, Penagos; } \\ \text { León } & : \text { Verdiago, Orzonaga; } \\ \text { Oviedo } & : \text { Cirviago; } \\ \text { Lugo } & : \text { Chavaga; } \\ \text { La Coruña } & : \text { Irago; } \\ \text { Pontevedra } & : \text { Couñago, Sulago. }\end{array}$

Evidentemente estamos muy lejos de encontrar una densidad de sufijos - acu que sea comparable con la de la Galia meridional. Por eso, hemos de pensar en multiplicar los jalones, ayudándonos con otro sufijo característico de la ocupación gala, el sufijo átono -icu .

"Por otra parte, escribe Dauzat" ${ }^{\text {, }}$-anum puede ser reforzado con el sufijo -icum : Celsimanica, Sauxillanges ; Julianica, Julianges ; Mallianicum, Malliargues ; Marcellianicum, Marsillargues, Massilargues, etc. (el final se volvió -argue en el mediodía, -ange en femenino más al norte)".

En regiones particularmente conservadoras, este sufijo -icu puede aparecer

7 C. Plinio Sec. Hist. nat., III, 22.

8 Julio Caro Baroja. Los pueblos del Norte. San Sebastián, 1973, p. 44.

9 Albert Dauzat. Op. cit., p. 129. 


\section{LAS HUELLAS DE LOS GALOS}

sin caída de la vocal postónica, sólo con sonorización de la consonante sorda intervocálica:

$\begin{array}{ll}\text { Huesca } & \text { : Sabiñánigo } \\ \text { Zaragoza } & \text { : Anzánigo; } \\ \text { Navarra } & \text { : Cintruénigo; } \\ \text { Santander } & : \text { Cabuérniga, Padiénigo; } \\ \text { Lugo } & \text { :Sasdónigas. }\end{array}$

Con caída de la vocal postónica, tenemos que esperar terminaciones en $-n g o /-n g a^{11}$.

$\begin{array}{ll}\text { Soria } & : \text { Berlanga; } \\ \text { Burgos } & : \text { Gayangos, Mijangos; } \\ \text { Oviedo } & : \text { Cangas, Caranga, Carangas; } \\ \text { Lugo } & : \text { Balonga, Cangas; } \\ \text { La Coruña } & : \text { Aranga; } \\ \text { Pontevedra } & : \text { Balongo, Cangas } .\end{array}$

Transcribimos en un mapa todos estos topónimos, Después de bajar el Gállego, con los jalones de Sabiñánigo y Anzánigo, nos enseñan un grupo importante de establecimientos galos instalados al sur del Ebro, cerca de Gallur, entre el valle del Jalón y el del Linares, subafluente del Ebro. Los siete puntos van repartidos entre las provincias de Zaragoza, Soria, Navarra y Logroño, esta última provincia con el único punto de Cornago, en su extremo sudeste, fuera de sus partes ocupadas por vascones y berones. Esta instalación se hace, pues, a costa de la tribu celtíbera de los pelindones. Notamos que los galos han dado la vuelta al territorio de los vascones sin penetrar en él.

Las huellas siguientes no nos aparecen sino en la parte de la provincia de Burgos situada al norte del Ebro. Desde allí serán continuas al norte de la Cordillera Cantábrica por las provincias de Santander, Oviedo, Lugo, La Coruña y Pontevedra.

¿Qué deja suponer el hiato entre los dos extremos de la Rioja? Probablemente los recién llegados no pudieron fundar establecimientos en el territorio de los berones; tampoco lo hicieron en el de los vascones, várdulos y caristios, al norte del Ebro. No vuelven a aparecer sino entre los autrigones.

Para llegar a éstos tuvieron que pasar al norte o al sur de los berones. Si hubieran pasado al sur, habrían tenido que meterse por la Meseta, atravesar el territorio de los turmogos, pasar los Montes de Oca, volver a bajar hacia el

10 Ramón Menéndez Pidal. Orígenes del español. Madrid, 1964,p. 174. A propósito de Sabiñánigo (y otros topónimos) escribe: "Pero junto a éstos abundan otros nombres con $-o$, que no pueden ser de origen tardío...".

11 Ramón Menéndez Pidal. Op. cit., pp. 56 y 163. Da el ejemplo: "Mescanigos 1065, hoy Mijangos, partido de Villarcayo". 


\section{ENRIQUE GUITER}

valle del Ebro, y alcanzar por el sur el territorio de los autrigones. Tal trayecto resultaba difícil; además no hallamos huellas galas en la parte del territorio de los autrigones situada al sur del Ebro: no las vemos sino al norte del río.

Parece, pues, que, con una maniobra comparable con la que habían realizado a lo largo del Gállego, los galos se fueron río arriba, aprovechando su situación fronteriza entre berones $\mathrm{y}$ vascones.

Entre las provincias de Burgos y Santander la altitud de la Cordillera Cantábrica queda bastante moderada: el Puerto de los Tornos no sube a más de $796 \mathrm{~m}$. La marcha hacia el occidente se prosigue ahora por las partes septentrionales de los territorios cántabro y asture; por fin llega a las provincias de Lugo, La Coruña y Pontevedra.

El mapa de la obra de J. Caro Baroja, al cual ya nos referimos ${ }^{8}$, limita la extensión de los "Galaicos" a las tres provincias de Lugo, La Coruña y Pontevedra, excluyendo la de Orense. Este punto de vista parece confirmado por el estudio toponímico.

En conclusión, el examen de los topónimos sostiene la hipótesis de un trayecto de los Galos desde el Gállego hasta Galicia. Este trayecto va jalonado por los establecimientos de los migradores que se pararon por el camino. Pero hay en la Rioja una discontinuación extraña que intentamos explicar. 